\title{
Response to Martin Ravallion
}

\author{
Jeni Klugman · Francisco Rodríguez • Hyung-Jin Choi
}

Published online: 9 September 2011

(C) Springer Science+Business Media, LLC 2011

In our paper "The HDI 2010: New Controversies, Old Critiques", published in the June 2011 issue of the Journal of Economic Inequality, we responded to several of Martin Ravallion's criticisms of the HDI functional form, arguing that they were for the most part misplaced [1]. In his article in this issue, Ravallion [2] presents several counterarguments. He argues that the fact that the HDI is not a comprehensive objective function should not deter us from studying its trade-offs; that the HDR in practice advocates for maximization of the HDI; and that concavity in income is not an exclusive property of the new HDI's functional form. He also restates his criticisms of the relative weights of longevity and education and the gradient of the valuation of longevity in income.

We agree that the incompleteness of the HDI should not deter us from studying the trade-offs of the index. In fact, we are puzzled as to why Ravallion characterizes our argument as being that one should "not care about the trade-offs." We sought to stress the relevance of understanding these trade-offs and their properties, writing that they "are extremely relevant as they tell us about the marginal contributions of improvements in different dimensions to furthering capabilities."

What we do argue is that the interpretation of these trade-offs should be consistent with the nature and purpose of the HDI, which is best viewed as that of providing an index of capabilities. Thus we caution against interpreting the trade-offs implicit in the index as social valuations and trying to directly derive policy recommendations from them.

In particular, we take issue with Ravallion's interpretation of a positive income gradient in the valuation of longevity as a life being worth more in rich countries.

\author{
J. Klugman ( $\otimes)$ \\ Gender and Development Group, The World Bank, Washington DC, USA \\ e-mail: jklugman@worldbank.org \\ F. Rodríguez \\ Global Emerging Markets Research, Bank of America Merrill Lynch, New York, NY, USA
}

H.-J. Choi

Department of Economics, University of Minnesota, Minneapolis, MN, USA 
The idea of the HDI as a capabilities index-which forms the basis of the argument presented in our paper, to which Ravallion pays scant attention-is key to understanding why this comparison is wrong. In rich countries, income contributes very little to further expanding capabilities, as the basic material conditions necessary for pursuing meaningful lives have been attained for most residents. Therefore the "value" of anything in terms of income appears very high. A comparison of trade-offs between poor and rich countries only tells us that, in terms of its capacity to improve capabilities, income is nearly worthless in rich countries. One cannot and should not jump from this to the conclusion that one should devote more resources to increasing longevity in rich countries rather than in poor countries.

For the same reason, comparing the marginal rates of substitution of education for income with Mincerian returns does not provide meaningful insights. The comparison reveals that an index of capabilities attributes much more relevance to education relative to income than the relative relevance assigned by participants in markets. But it would in fact be odd if this were not the case.

The fact that the HDI is an index of capabilities is also relevant for understanding why our functional form uses the logarithmic transformation of income combined with the geometric mean, a double concavity which Ravallion harshly criticizes. Ravallion actually states that we "do not explain why" we use two concave transformations rather than just one in our functional form. This statement is puzzling, as our paper argues in detail that this is necessary because of the distinction between the existence of diminishing returns in the transformation of capabilities into the HDI and diminishing returns in the transformation of income into capabilities. As we write, "the geometric mean ensures that there are diminishing returns in each [capability]... the natural logarithm captures the fact that there are also diminishing returns in the transformation of income into capabilities."

Nor do we argue, as Ravallion states, that improving the HDI should not be a development objective. In fact, we write "Expanding these freedoms should be one objective-and a very important one-of society. However, there is no contention that it should be the only objective".

Ravallion makes this statement in the context of arguing that in order to be consistent with our position, we should be able to point to cases where an improvement in the HDI was seen as negative. This is a non-sequitur: the HDI can be one of many arguments of a social welfare function without its marginal contribution ever being negative. Our argument is that the expansion of capabilities is one but not the only socially relevant objective-this is clearly distinct from the argument, which we do not make, that the expansion of capabilities could be harmful to social welfare.

In any case, there are multiple instances in which the HDR has highlighted the incompleteness of the HDI and shown how rankings can and do change once one considers factors that are not in the HDI. To take one of many examples, the 1990 HDR showed how country rankings could change for several countries by adjusting for income inequality, ${ }_{1}^{1}$ an exercise that was expanded to 139 countries and three dimensions of inequality in the 2010 HDI. As we wrote in chapter 4 of

\footnotetext{
${ }^{1}$ Box 1.3 of the 1990 HDR considers adjustments to GNP for inequality (using the Gini) for Panama, Brazil, Malaysia and Costa Rica, and discusses the ability to make similar adjustments for the HDI (although it does not actually do so). It finds that "if distributional adjustments are made using each country's Gini coefficient, the original ranking reverses to Costa Rica, Malaysia, Brazil, Panama”: [3]
} 
the 2010 HDR: "Countries may have a high HDI and be undemocratic, inequitable and unsustainable-just as they may have a low HDI and be relatively democratic, equitable and sustainable... we cannot be sure that increases in the HDI will be accompanied by improvements in the broader dimensions of human development or that improvements in those dimensions will yield increases in the HDI."

Some of Ravallion's critiques are nonetheless useful. We accept that the relative valuation of longevity in very poor countries like Zimbabwe in 2010 is unreasonably low. We recognize this in our paper, where we also argue that the problems may be due not just to the lower bound but also to poor quality statistics and biases in national income accounting practices. For this reason, and in line with Ravallion's suggestion, the 2011 HDI will use a lower subsistence level of income, $\$ 100$, as a lower bound. This change is due in no small measure to the valuable discussions prompted by Ravallion's criticisms, a contribution which we are glad to acknowledge.

\section{References}

1. Klugman, J., Rodríguez, F., Choi, H.-J.: The HDI 2010: New controversies, old critiques. J. Econ. Inequal. 9(2), 249-288 (2011)

2. Ravallion, M.: The human development index: a response to Klugman, Rodríguez and Choi. J. Econ. Inequal. (2011). doi:10.1007/s10888-011-9193-0

3. UNDP-HDRO. Human Development Report. Oxford University Press, New York (1990) 